\title{
Celecoxib does not significantly delay bone healing in a rat femoral osteotomy model: a bone histomorphometry study
}

This article was published in the following Dove Press journal:

Orthopedic Research and Reviews

8 December 201 I

Number of times this article has been viewed

Jun Iwamoto'

Azusa Seki ${ }^{2}$

Yoshihiro Sato ${ }^{3}$

Hideo Matsumoto'

'Institute for Integrated Sports Medicine, Keio University School of Medicine, Tokyo, Japan; ${ }^{2} \mathrm{Hamri}$ Co, Ltd, Tokyo, Japan; ${ }^{3}$ Department of Neurology, Mitate Hospital, Fukuoka, Japan
Correspondence: Jun Iwamoto Institute for Integrated Sports Medicine, Keio University School of Medicine, 35 Shinanomachi, Shinjuku-ku,

Tokyo 160-8582, Japan

Tel +8I 33353 I2। I

Fax +8I 333529467

Email jiwamoto@a8.keio.jp
Background and objective: The objective of the present study was to determine whether celecoxib, a cyclo-oxygenase-2 inhibitor, would delay bone healing in a rat femoral osteotomy model by examining bone histomorphometry parameters.

Methods: Twenty-one 6-week-old female Sprague-Dawley rats underwent a unilateral osteotomy of the femoral diaphysis followed by intramedullary wire fixation; the rats were then divided into three groups: the vehicle administration group (control, $\mathrm{n}=8$ ), the vitamin $\mathrm{K}_{2}$ administration (menatetrenone $30 \mathrm{mg} / \mathrm{kg}$ orally, five times a week) group (positive control, $\mathrm{n}=5$ ), and the celecoxib administration $(4 \mathrm{mg} / \mathrm{kg}$ orally, five times a week) group $(\mathrm{n}=8)$. After 6 weeks of treatment, the wires were removed, and a bone histomorphometric analysis was performed on the bone tissue inside the callus. The lamellar area relative to the bone area was significantly higher and the total area and woven area relative to the bone area were significantly lower in the vitamin $\mathrm{K}_{2}$ group than in the vehicle group. However, none of the structural parameters, such as the callus and bone area relative to the total area, lamellar and woven areas relative to the bone area, or the formative and resorptive parameters such as osteoclast surface, number of osteoclasts, osteoblast surface, osteoid surface, eroded surface, and bone formation rate per bone surface differed significantly between the vehicle and celecoxib groups.

Conclusion: The present study implies that celecoxib may not significantly delay bone healing in a rat femoral osteotomy model based on the results of a bone histomorphometric analysis.

Keywords: femoral osteotomy, bone healing, callus, rat, celecoxib

\section{Background}

Conventional non-steroidal anti-inflammatory drugs (NSAIDs) suppress both cyclo-oxygenase-1 (COX-1) and cyclo-oxygenase-2 (COX-2). ${ }^{1}$ The adverse gastrointestinal effects (such as life-threatening bleeding or the perforation of gastro-duodenal ulcers) of conventional NSAIDs are associated with the inhibition of COX-1, while the desired analgesic, anti-inflammatory, and antipyretic effects are derived from COX-2 inhibition. ${ }^{1}$ COX-2 inhibitors (celecoxib, rofecoxib), a newer generation of NSAIDs, exhibit analgesic and anti-inflammatory effects equivalent or superior to those of conventional NSAIDs (aspirin, indomethacin), while reducing the prevalence of adverse gastrointestinal events. ${ }^{2}$ Because of these advantages, the use of COX-2 inhibitors for the treatment of pain and arthritis has become widespread. COX-2 inhibitors are presently available for the management of pain associated with musculoskeletal trauma, including fractures.

The process of bone fracture healing has been clarified. ${ }^{3,4}$ Bone fractures initiate a response that begins with inflammation (the cellular and vascular response to injury), 
proceeds through repair (the replacement of damaged or lost cells and matrices with new cells and matrices), and ends with remodeling (removal, replacement, and reorganization of the repair tissue, usually along lines of mechanical stress). ${ }^{3}$ During the bone fracture healing process (1) periosteal osteoblast proliferation and intramembranous ossification at the fracture site; (2) cell proliferation and migration into the fracture site; and (3) chondrocyte differentiation in the soft callus with subsequent endochondral ossification are stimulated. ${ }^{4}$ Then, remodeling of the fracture callus by osteoclastic resorption and subsequent osteogenesis converts woven bone into lamellar bone, thereby restoring the shape and mechanical integrity of the fractured bone. ${ }^{4}$ Because COX-2 is induced at inflammation sites, and prostaglandins, which are believed to stimulate bone formation and resorption, can mediate certain events in fracture healing, ${ }^{4,5} \mathrm{COX}-2$ inhibitors likely modify the inflammation phase and may delay bone healing.

Although several studies have demonstrated inhibitory effects of COX-2 inhibitors on bone healing in several animal models, ${ }^{4,6-8}$ other studies did not find any significant effect of COX-2 inhibitors on bone healing. ${ }^{9,10}$ Thus, the use of COX-2 inhibitors for the management of pain and inflammation caused by fractures remains controversial. At present, several studies have clarified the influence of anti-fracture medicines on bone healing in rat femoral fracture or osteotomy models using bone histomorphometry parameters. ${ }^{1-13}$ However, very few studies have shown the influence of celecoxib on bone healing in animal models from the viewpoint of bone histomorphometry. The hypothesis of the present study was that the COX-2 inhibitor celecoxib would modify bone formation and resorption as evaluated by bone histomorphometric analyses and subsequently influence bone healing in a rat femoral osteotomy model. The purpose of the present study was to determine whether celecoxib would delay bone healing in a rat femoral osteotomy model by measuring bone histomorphometry parameters. Because vitamin $\mathrm{K}_{2}$ (menatetrenone) was reported to promote bone healing in a rat femoral osteotomy model with or without glucocorticoid treatment, ${ }^{13}$ rats treated with vitamin $\mathrm{K}_{2}$ were used as positive controls.

\section{Methods}

\section{Treatment of animals}

Thirty 5-week-old female Sprague-Dawley rats were purchased from Charles River Japan (Kanagawa, Japan). The rats were fed a pelleted standard chow diet containing $1.25 \%$ calcium, $0.9 \%$ phosphorus, and $618 \mathrm{IU} / 100 \mathrm{~g}$ of vitamin $\mathrm{D}_{3}$ (CRF-1; Oriental Yeast, Co, Ltd, Tokyo, Japan). The animals were housed under local vivarium conditions (temperature, $24^{\circ} \mathrm{C}$; humidity, 50\%; and a 12-hour on/off light cycle), with free access to water. After allowing 1 week for adaptation to the new environment, the 6-week-old rats were subjected to a unilateral osteotomy at the mid-diaphysis of the left femur, followed by intramedullary wire fixation under general anesthesia induced by the intraperitoneal injection of $25-30 \mathrm{mg} / \mathrm{kg}$ of pentobarbital sodium (Schering-Plough Animal Health, Co, Ltd, Tokyo, Japan), together with auxiliary anesthesia via the inhalation of 2\%-3\% isoflurane (Mylan Inc, Tokyo, Japan) using the Table Top Laboratory Animal Anesthesia System (V1 Type; VetEquip, Inc, CA). The rats were then randomized using the stratified weight method into three groups $(n=10$ in each group): the vehicle administration (control) group; the vitamin $\mathrm{K}_{2}$ administration (positive control) group; and the celecoxib administration group. Celecoxib (Pfizer Inc, New York, NY) was suspended in 5\% methylcellulose at a dosage of $4 \mathrm{mg} / \mathrm{kg}$ body weight and administered by gavage deep into the mouth 5 times a week. The metabolism of celecoxib across several species, including mouse, rat, rabbit, dog, and monkey, has been shown to be similar to human metabolism. ${ }^{14,15}$ The administration of celecoxib at a dose of $4 \mathrm{mg} / \mathrm{kg}$ daily may correspond to a clinical dose, since the recommended human maximum daily dose of celecoxib is $200 \mathrm{mg}$ twice a day. Vitamin $\mathrm{K}_{2}$ (menatetrenone; Eisai Co, Ltd, Tokyo, Japan) was suspended in fatty acid (Miglyol 812; Mitsuba Trading, Co, Ltd, Tokyo, Japan) at a dosage of $30 \mathrm{mg} / \mathrm{kg}$ body weight and administered by gavage deep into the mouth 5 times a week. ${ }^{13}$ The body weight of the rats was monitored weekly, and the total duration of the experiment was 6 weeks. Two rats in the vehicle group, 3 rats in the vitamin $\mathrm{K}_{2}$ group, and 2 rats in the celecoxib group were omitted because radiographic and bone histomorphometric analyses showed primary healing of the osteotomy site. Two rats in the in the vitamin $\mathrm{K}_{2}$ group were also omitted because of operative failure (severe deformity and pseudoarthrosis). Therefore, a total of 21 rats ( 8 rats each in the vehicle control and celecoxib groups and 5 rats in the vitamin $\mathrm{K}_{2}$ group) were analyzed. The present experiment was performed at the laboratory of Hamri Co, Ltd. (Ibaraki, Japan), which has been approved by the Association for the Assessment and Accreditation of Laboratory Animal Care (AAALAC) International. The experimental protocol was approved by the Institutional Animal Care and Use Committee (IACUC) of Hamri Co, Ltd. (Ibaraki, Japan).

\section{Preparation of specimens}

All the rats were labeled with $10 \mathrm{mg} / \mathrm{kg}$ calcein (Dojindo Laboratories, Kumamoto, Japan) injected subcutaneously at 7 and 3 days before death. At 6 weeks after the 
start of the experiment, the animals were sacrificed by exsanguination after being anesthetized via the inhalation of 2\%-3\% isoflurane (Mylan Inc, Tokyo, Japan) using the Table Top Laboratory Animal Anesthesia System (V1 Type; VetEquip, Inc, CA). Bilateral femora were isolated from each animal, and soft X-ray radiographs of the bones were taken. After the lengths of the bilateral femora were measured using a dial caliper, the left femur was processed for the bone histomorphometric analyses.

\section{Radiographs}

Anteroposterior and lateral soft X-ray radiographs of the bilateral femora were made using SOFTEX M-60 (Softex Co, Ltd, Kanagawa, Japan). Radiographs were investigated by two investigators familiar with bone healing in rats to determine the degree of bone healing. Consensus regarding union, incomplete union, and nonunion was obtained between the two investigators. Figure 1 shows representative anteroposterior soft X-ray radiographs of the bilateral femora. For the osteotomized femur, bone healing was considered as (a) union if bone bridging at the osteotomy site existed but an osteotomy line disappeared, (b) incomplete union if some new bone bridging at the osteotomy site was evident but an osteotomy line existed, and (c) nonunion if an osteotomy line was evident and bone bridging failed to be formed despite callus formation. Bone bridging at the osteotomy site was determined by comparing the intact and osteotomized femora. Radiographs were not quantitatively scored.

\section{Bone histomorphometric analysis of osteotomy site at the femoral diaphysis}

The left osteotomized femur was cut into three parts with a Diamond Band Saw (EXAKT BS 3000, Norderstedt, Germany), and the diaphysis including the osteotomy site was stained according to the method of Villanueva. ${ }^{16}$ After dehydration with ethanol and acetone, the bone tissue was embedded in methyl methacrylate (Wako Pure Chemical, Osaka, Japan). Cross-sections of an area within 500- $\mu \mathrm{m}$ distal from the original osteotomy line were cut at a thickness of 20-30 $\mu \mathrm{m}$ using a microgrinder (Exakt KG 4000, Germany). Then, the specimens were observed under a fluorescence microscope (Zeiss Axiplan 2, Jena, Germany) coupled with a video camera (CCD Color Camera CS 5270 I; Tokyo Electronic Industry Co, Ltd, Tokyo, Japan). A bone morphometry software program (Winroof Version 3.5, Mitani Corporation, Toyoshima Fukui City, Japan) was used for the histomorphometric analysis. Static and dynamic bone histomorphometry measurements were performed on the bone tissue inside the callus. Polarized light was applied to distinguish lamellar bone from woven bone.

The measured parameters of the osteotomy site were total area (total Ar), callus Ar, bone Ar, lamellar Ar, woven Ar, bone surface (BS), osteoclast surface (OcS), number of osteoclasts (N.Oc), osteoblast surface (ObS), osteoid surface (OS), eroded surface (ES), single and double labeling surface (sLS and dLS, respectively), and the interlabel width, in accordance with the method described by Li et al and Cao et al. ${ }^{11,12}$ These data were used to calculate callus Ar/total
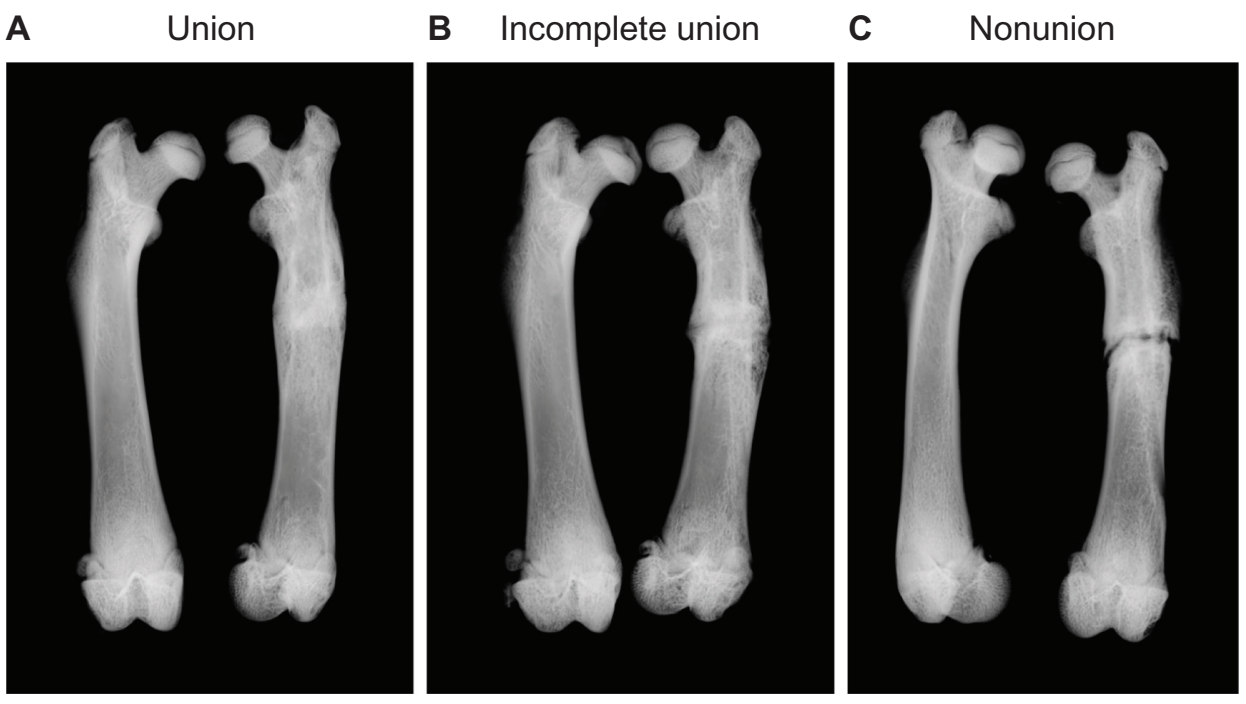

Figure I Classification of degree of bone healing. In each photo, the left bone is the right intact femur and the right bone is the left osteotomized femur. For the osteotomized femur, bone healing was considered as (A) union if bone bridging at the osteotomy site existed but an osteotomy line disappeared, (B) incomplete union if some new bone bridging at the osteotomy site was evident but an osteotomy line existed, and (C) nonunion if an osteotomy line was evident and bone bridging failed to be formed despite callus formation. 
Ar, bone Ar/total Ar, lamellar Ar/bone Ar, woven Ar/bone Ar, OcS/BS, N.Oc/BS, ObS/BS, OS/BS, ES/BS, and bone formation rate/BS (BFR/BS). ${ }^{11,12,17}$

\section{Statistical analysis}

All the data were expressed as means and standard deviations (SD). Comparisons of data among three groups were performed using an analysis of variance (ANOVA) with the Fisher protected least significant difference (PLSD) test or the Fisher exact test. All statistical analyses were performed using the Stat View J-5.0 program (SAS Institute Inc, Cary, NC) on a Windows computer. A significance level of $P<0.05$ was used for all the comparisons.

\section{Results}

\section{Body weight and femoral length}

Table 1 shows that the initial and final body weights did not differ significantly among the three groups. The bone length of the intact and osteotomized femora also did not differ significantly among the three groups.

\section{Radiology}

Table 2 shows the results of the soft X-ray radiographic analysis. No significant differences in the frequency of union, incomplete union, and nonunion were observed among three groups.

\section{Bone histomorphometric analysis of osteotomy site at the femoral diaphysis}

Table 3 shows that the lamellar Ar/bone Ar was significantly higher and the total Ar and woven area/bone Ar were significantly lower in the vitamin $\mathrm{K}_{2}$ group than in the vehicle group. However, callus Ar, bone Ar, callus Ar/total Ar, bone Ar/total Ar, OcS/BS, N.Oc/BS, ObS/BS, OS/BS, ES/BS, and $\mathrm{BFR} / \mathrm{BS}$ did not differ significantly between the vehicle and vitamin $\mathrm{K}_{2}$ groups.

Table I Body weight and femoral length

\begin{tabular}{llll}
\hline & $\begin{array}{l}\text { Vehicle } \\
(\mathbf{n = 8})\end{array}$ & $\begin{array}{l}\text { Celecoxib } \\
(\mathbf{n = 8})\end{array}$ & $\begin{array}{l}\text { Vitamin K }_{2} \\
(\mathbf{n}=\mathbf{5})\end{array}$ \\
\hline Initial body weight $(\mathrm{g})$ & $\mathrm{I} 65.1 \pm 10.8$ & $164.3 \pm 10.1$ & $163.4 \pm 5.2$ \\
Final body weight $(\mathrm{g})$ & $267.5 \pm 30.2$ & $269.8 \pm 16.4$ & $250.5 \pm 31.0$ \\
$\begin{array}{l}\text { Femoral length }(\mathrm{mm}) \\
\text { Osteotomy side }\end{array}$ & $33.7 \pm 1.0$ & $33.0 \pm 1.2$ & $33.8 \pm 0.5$ \\
Intact side & $33.8 \pm 0.7$ & $33.6 \pm 0.5$ & $33.8 \pm 0.5$ \\
\hline
\end{tabular}

Notes: Data are expressed as means \pm SD. An ANOVA with the Fisher PLSD test was used to compare the data among three groups. The initial and final body weights and the bone length of the intact and osteotomized femora did not differ significantly among three groups.
Table 2 Frequency of union, incomplete union, and nonunion

\begin{tabular}{llll}
\hline & $\begin{array}{l}\text { Vehicle } \\
(\mathbf{n = 8 )}\end{array}$ & $\begin{array}{l}\text { Celecoxib } \\
(\mathbf{n}=\mathbf{8})\end{array}$ & $\begin{array}{l}\text { Vitamin } \mathrm{K}_{2} \\
(\mathbf{n}=\mathbf{5})\end{array}$ \\
\hline Union & 6 & 5 & 3 \\
Incomplete union & 2 & 2 & $\mathrm{I}$ \\
Nonunion & 0 & $\mathrm{I}$ & $\mathrm{I}$ \\
\hline
\end{tabular}

Notes: The Fisher exact test was used to compare the data among three groups. No significant differences in the frequency of union, incomplete union, and nonunion were observed among three groups.

Table 3 also shows that the total Ar, callus Ar, bone Ar, callus Ar/total Ar, and bone Ar/total Ar did not differ significantly between the vehicle and celecoxib groups. The lamellar Ar/bone Ar tended to be higher, and the woven Ar/bone Ar tended to be lower in the celecoxib group than in the vehicle group, but these differences were not statistically significant. The OcS/BS and the N.Oc/BS tended to be higher and the $\mathrm{ObS} / \mathrm{BS}$ and the BFR/BS tended to be lower in the celecoxib group than in the vehicle group, but these differences were not statistically significant. The OS/BS and the ES/BS were not significantly different between the vehicle and celecoxib groups.

\section{Results of statistical analyses}

$P$ values of all statistical analyses are shown in Table 4 .

\section{Histology}

Figure 2 shows cross-section microphotographs of the bone tissue inside the callus with Villanueva Osteochrome Bone

Table 3 Bone histomorphometric analysis of osteotomy site at the femoral diaphysis

\begin{tabular}{llll}
\hline & $\begin{array}{l}\text { Vehicle } \\
(\mathbf{n}=\mathbf{8})\end{array}$ & $\begin{array}{l}\text { Celecoxib } \\
(\mathbf{n}=\mathbf{8})\end{array}$ & $\begin{array}{l}\text { Vitamin } \mathbf{K}_{2} \\
(\mathbf{n}=\mathbf{5})\end{array}$ \\
\hline Total Ar (mm) & $17.7 \pm 4.9$ & $14.5 \pm 3.9$ & $12.2 \pm 4.2^{\mathrm{a}}$ \\
Callus Ar (mm) & $7.84 \pm 4.74$ & $7.52 \pm 3.79$ & $4.23 \pm 3.3 \mathrm{I}$ \\
Bone Ar (mm) & $4.22 \pm 1.99$ & $4.31 \pm 2.00$ & $2.75 \pm 1.98$ \\
Callus Ar/total Ar (\%) & $42.4 \pm 20.5$ & $48.8 \pm 18.4$ & $30.8 \pm 16.6$ \\
Bone Ar/total Ar (\%) & $23.7 \pm 8.9$ & $29.0 \pm 10.7$ & $20.6 \pm 10.5$ \\
Lamellar Ar/bone Ar (\%) & $27.0 \pm 9.8$ & $23.9 \pm 13.2$ & $40.4 \pm 6.6^{\mathrm{a}, \mathrm{b}}$ \\
Woven Ar/bone Ar (\%) & $73.0 \pm 9.8$ & $76.1 \pm 13.2$ & $59.6 \pm 6.6^{\mathrm{a}, \mathrm{b}}$ \\
OcS/BS (\%) & $0.92 \pm 0.57$ & $1.43 \pm 1.22$ & $0.74 \pm 0.54$ \\
N. Oc/BS (\#/mm) & $0.32 \pm 0.20$ & $0.49 \pm 0.40$ & $0.25 \pm 0.17$ \\
ObS/BS (\%) & $18.3 \pm 4.3$ & $12.7 \pm 6.1$ & $18.4 \pm 8.8$ \\
OS/BS (\%) & $29.7 \pm 7.2$ & $28.3 \pm 9.5$ & $31.2 \pm 9.3$ \\
ES/BS (\%) & $27.6 \pm 9.7$ & $28.2 \pm 9.9$ & $27.3 \pm 6.5$ \\
BFR/BS $\left(\mu m^{3} / \mu m^{2} /\right.$ day) & $0.79 \pm 0.24$ & $0.65 \pm 0.21$ & $0.92 \pm 0.22^{\mathrm{a}}$ \\
\hline
\end{tabular}

Notes: Data are expressed as means \pm SD. An ANOVA with the Fisher PLSD test was used to compare the data among three groups. $P<0.05$ vs vehicle group; ${ }^{b P}<0.05$ vs celecoxib group.

Abbreviations: Ar, area; OcS, osteoclast surface; BS, bone surface; N. Oc, number of osteoclasts; ObS, osteoblast surface; OS, osteoid surface; ES, eroded surface; BFR, bone formation rate. 
Table $4 P$ values of all statistical analyses

\begin{tabular}{llll}
\hline & $\begin{array}{l}\text { Vehicle vs } \\
\text { celecoxib }\end{array}$ & $\begin{array}{l}\text { Vehicle vs } \\
\text { vitamin } \mathbf{K}_{2}\end{array}$ & $\begin{array}{l}\text { Celecoxib vs } \\
\text { vitamin } \mathbf{K}_{2}\end{array}$ \\
\hline Initial body weight & 0.8689 & 0.7602 & 0.8724 \\
Final body weight & 0.8582 & 0.2665 & $0.208 \mathrm{I}$ \\
Femoral length & & & \\
$\quad$ Osteotomy side & 0.5061 & 0.9516 & 0.4992 \\
$\quad$ Intact side & 0.2177 & 0.9049 & 0.2086 \\
Frequency of union & $>0.9999$ & $>0.9999$ & $>0.9999$ \\
Total Ar & 0.1570 & 0.0406 & 0.3745 \\
Callus Ar & 0.8789 & 0.1391 & 0.1749 \\
Bone Ar & 0.9247 & 0.2111 & 0.1842 \\
Callus Ar/total Ar & 0.5056 & 0.2958 & 0.1117 \\
Bone Ar/total Ar & 0.3022 & 0.5927 & 0.1572 \\
Lamellar Ar/bone Ar & 0.5774 & 0.0387 & 0.0157 \\
Woven Ar/bone Ar & 0.5774 & 0.0387 & 0.0157 \\
OcS/BS & 0.2591 & 0.7238 & 0.1842 \\
$\mathrm{~N}$. Oc/BS & 0.2772 & 0.6811 & 0.1784 \\
ObS/BS & 0.0874 & 0.9758 & 0.1234 \\
OS/BS & 0.7378 & 0.7755 & 0.5640 \\
ES/BS & 0.8922 & 0.9595 & 0.8653 \\
BFR/BS & 0.2233 & 0.2954 & 0.0425 \\
\hline Note: Expla & &
\end{tabular}

Note: Explanations of abbreviations are shown in tables I, II, and III.

staining under non-epifluorescent light (A), epifluorescent light (B), and polarized light (C). The findings are consistent with those of the bone histomorphometric analyses. In particular, lamellar bone formation is more active in the vitamin $\mathrm{K}_{2}$ group than in the vehicle group.

\section{Discussion}

The purpose of the present study was to examine the influence of celecoxib (a newer selective COX-2 inhibitor) on bone healing in a rat femoral osteotomy model by measuring bone histomorphometry parameters. Celecoxib did not significantly influence structural parameters, such as the callus and bone areas relative to the total area, the lamellar and woven areas relative to the bone area, and the formative and resorptive parameters inside the callus. The present study showed that celecoxib did not significantly delay bone healing in a rat femoral osteotomy model.

COX-2 is induced at inflammation sites, and prostaglandins, which are believed to stimulate bone formation and resorption, can mediate certain events in fracture healing.,5 COX-2 activity is essential for prostaglandin production and endochondral ossification during fracture healing. ${ }^{4}$ The inhibition of COX-2 activity by COX-2-specific NSAIDs not only suppresses inflammation, but also impedes the synthesis of prostaglandins, reducing osteogenesis as indicated by a reduction in alkaline phosphatase and the impairment of endochondral ossification: ${ }^{4,18,19}$ thus, selective COX-2 inhibitors should theoretically demonstrate adverse effects with regard to bone healing.

A review study has indicated that COX-2-selective inhibitors may not replace conventional NSAIDs for the short-term

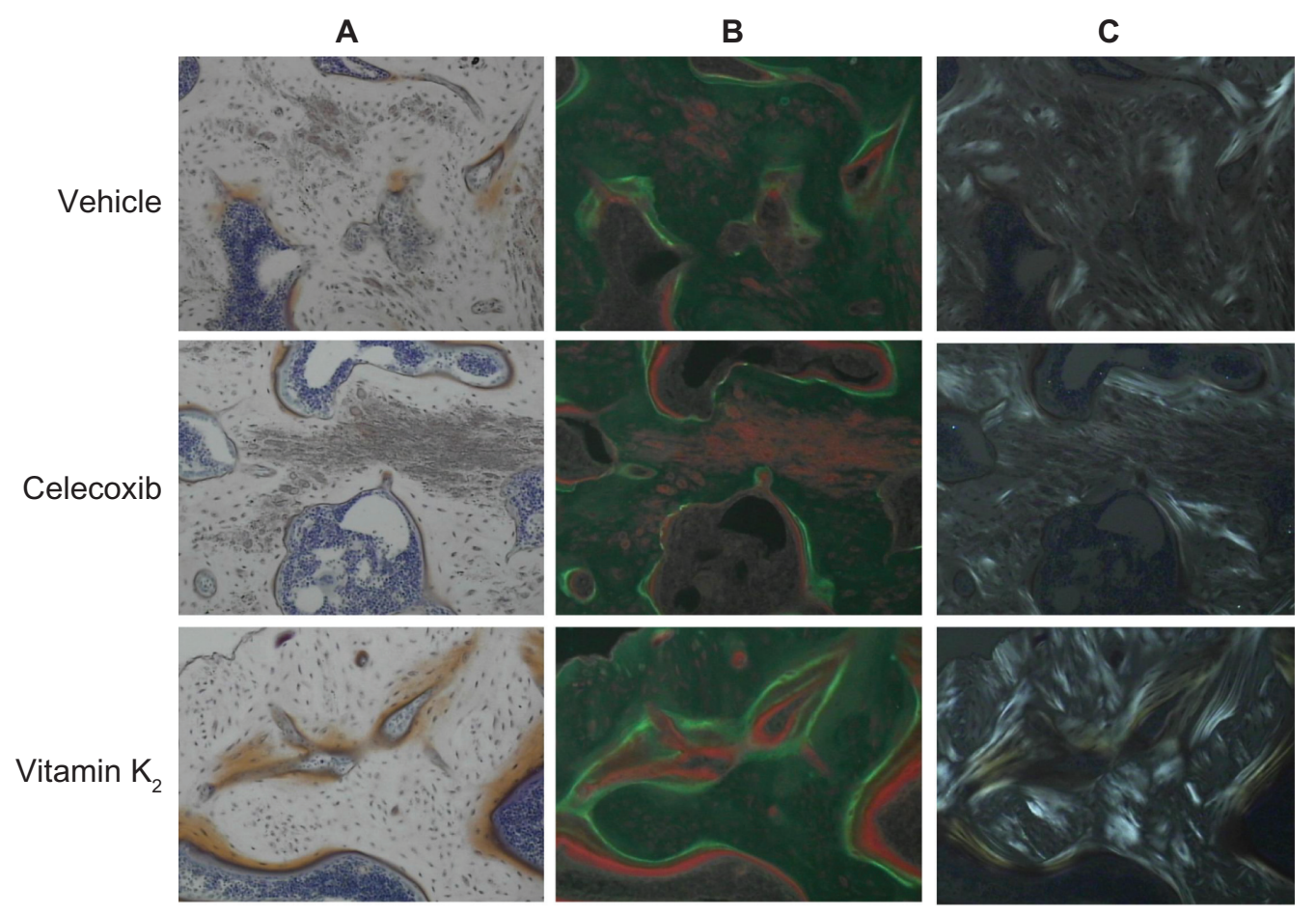

Figure 2 Microphotographs of bone tissue inside callus. The figures shows cross-section microphotographs of the bone tissue inside the callus with Villanueva Osteochrome Bone staining under non-epifluorescent light $(\mathbf{A})$, epifluorescent light $(\mathbf{B})$, and polarized light $(\mathbf{C})$. 
treatment of pain, ${ }^{20}$ suggesting that COX-2 inhibitors have a smaller influence on acute pain and inflammation, but not chronic pain and inflammation, than conventional NSAIDs. Several studies have shown that indomethacin, a conventional NSAID, delayed fracture healing in a rat closed femoral fracture model. ${ }^{21-23}$ However, Simon et $\mathrm{al}^{4}$ showed that fracture healing failed in a male rat closed femoral fracture model (age: 6-9 months, mean body weight $584 \mathrm{~g}$ ) treated with COX-2-selective NSAIDs (celecoxib $4 \mathrm{mg} / \mathrm{kg}$ daily and rofecoxib $3 \mathrm{mg} / \mathrm{kg}$ daily) for 8 weeks. Bergenstock et $\mathrm{al}^{6}$ reported that the 8 -week administration of celecoxib (3 or $6 \mathrm{mg} / \mathrm{kg}$ daily) impaired fracture healing in a female rat closed femoral fracture model (mean body weight $281 \mathrm{~g}$ ). Meanwhile, Herbenick et $\mathrm{al}^{7}$ reported that the 12 -week administration of celecoxib (5-30 mg/kg daily) reduced the biomechanical strength of the fracture callus in a male rat closed femoral fracture model (mean body weight: $350 \mathrm{~g}$ ).

Conversely, Gerstenfeld et $\mathrm{al}^{8}$ reported that the 5-week administration of a COX-2 selective NSAID, such as parecoxib (1.5 mg/kg daily), had only a small effect on the delay of fracture healing, even at doses that were known to fully inhibit prostaglandin production in a male rat sample, closed, transverse femoral fracture model (mean body weight: $450 \mathrm{~g}$ ). Brown et $\mathrm{al}^{9}$ reported that celecoxib ( $3 \mathrm{mg} / \mathrm{kg}$ daily) did not significantly delay fracture healing as seen at twelve weeks after fracture in a male rat nondisplaced femoral fracture model (mean body weight: $300 \mathrm{~g}$ ). Mullis et al ${ }^{10}$ reported that the 12 -week administration of celecoxib $(10$ or $50 \mathrm{mg} / \mathrm{kg}$ daily) and rofecoxib (1 or $5 \mathrm{mg} / \mathrm{kg}$ daily) did not significantly affect fracture healing in a male young mouse closed tibial fracture model (age: 8-10 weeks). Thus, reports regarding the inhibitory effect of celecoxib on bone healing in rodent fracture models remain contradictory. Although one possible explanation of the retardation of bone healing subsequent to the use of COX-2 inhibitors has been suggested to be the use of high doses and/or extended treatment periods, ${ }^{2}$ the above reports do not always support the idea that the dose of celecoxib, period of celecoxib administration, and age of rodents may affect bone healing. The degree of suppression of inflammation by celecoxib during the inflammation phase is considered to be a crucial factor in determining the influence of celecoxib on bone healing in rodents.

We used celecoxib at a dose of $4 \mathrm{mg} / \mathrm{kg} 5$ times a week, which may correspond to a clinically relevant dose. The duration of celecoxib administration was 6 weeks, because bone histomorphometric analyses are thought to be appropriate when performed on the callus during the remodeling phase; not only bone formation and resorption, but also woven and lamellar bone and callus volumes were evaluated. ${ }^{11-13}$ Very few studies have used bone histomorphometry to examine the influence of celecoxib on bone healing in rats. According to the results of the present study, treatment with clinically relevant doses of celecoxib may not significantly impair bone healing in a rat femoral osteotomy model. The procedures for the induction of the fracture or osteotomy and the methods used to evaluate bone healing (radiographic, histological, mechanical, and genetic) may have contributed to the varied results.

The bone histomorphometric analysis was performed only 6 weeks after the osteotomy, so whether celecoxib retarded the inflammation phase during bone healing remains unclear. Simon and O'Connor ${ }^{19}$ showed that celecoxib at a dose of $4 \mathrm{mg} / \mathrm{kg}$ for just 5 days reduced fracture healing in a female rat closed femoral fracture model (mean body weight: $272 \mathrm{~g}$ ); celecoxib therapy during the early stages of fracture repair reduced the fracture callus mechanical properties at a later stage of healing and increased the proportion of nonunions. In the present study, however, celecoxib might not have significantly influenced the inflammation phase, thereby resulting in non-significant influence on bone healing at 6 weeks after the osteotomy.

During the final stage of fracture repair, remodeling of tissue begins with the replacement of woven bone by lamellar bone and the resorption of the unneeded callus. ${ }^{3}$ The total mass of the fracture callus increases during repair and then decreases during remodeling, ${ }^{3}$ and bone turnover in terms of bone formation and resorption may gradually decrease as woven bone is replaced with lamellar bone. In the present study, celecoxib did not significantly affect the radiographic findings, bone resorption and formation, maturation of woven bone to lamellar bone, or callus volume in a rat femoral osteotomy model. These results implied that celecoxib did not significantly affect the repair and remodeling phases.

Femoral osteotomy rats treated with vitamin $\mathrm{K}_{2}$ were used as positive controls. Vitamin $\mathrm{K}_{2}$ reduced the total Ar and woven area/bone Ar and increased the lamellar Ar/bone Ar in a rat femoral osteotomy model. These trends were found in another study. ${ }^{13}$ Although the present study failed to find any significant changes in bone formation and resorption parameters between the vehicle and vitamin $\mathrm{K}_{2}$ groups, vitamin $\mathrm{K}_{2}$ might have stimulated the maturation of woven bone to lamellar bone and restored the shape and mechanical integrity of the osteotomized bone.

The strength of the present study was that bone histomorphometric analyses were adopted to examine bone formation and resorption as well as lamellar and woven bone inside the callus. However, several limitations are noted in the present study. 
First, the experimental period (6 weeks) may not have been enough to confirm the influence of celecoxib on bone healing at the osteotomy site. Thus, the long-term effect of celecoxib on bone healing remains uncertain. Second, the number of study subjects may not have been enough to obtain statistically significant results between the vehicle and celecoxib groups regarding the lamellar Ar/bone Ar, woven Ar/bone Ar, OcS/BS, N.Oc/BS, $\mathrm{ObS} / \mathrm{BS}$, and BFR/BS. Third, the celecoxib administration protocol ( 5 days a week) may not have been appropriate because 2 days of drug free time could limit the anti-inflammatory effect of the drug (the influence of acute celecoxib treatment) ${ }^{6}$ and subsequently affect bone healing process. Thus, further studies are needed to resolve these issues.

In conclusion, we conducted an experimental study to determine whether celecoxib would delay bone healing in a rat femoral osteotomy model by measuring bone histomorphometry parameters. The results of the present study imply that celecoxib may not significantly delay bone healing in this model. Although the present study adopted celecoxib administration at a dose of $4 \mathrm{mg} / \mathrm{kg}$ daily which might have corresponded to a clinical dose, clinical trials are needed to investigate the influence of celecoxib on bone healing in patients who suffered fractures of the long bone.

\section{Acknowledgment}

We thank Dr Toshimi Masaki (Mitani Institute for Bone Histomorphometry, Tokyo, Japan) for bone histomorphometric analysis.

\section{Disclosure}

All the authors state that they have no conflicts of interest in this work.

\section{References}

1. Hinz B, Brune K. Cyclooxygenase-2-10 years later. J Pharmacol Exp Ther. 2002;300(2):367-375.

2. Seidenberg AB, An YH. Is there an inhibitory effect of COX-2 inhibitors on bone healing? Pharmacol Res. 2004;50(2):151-156.

3. Buckwalter JA, Cruess RL. Healing of the musculoskeletal tissues. In: Rockwood CA, Green DP, Bucholz RW, editors. Rockwood and Green's Fractures in Adults. 3rd ed. Philadelphia: JB Lippincott; 1991:181-220.

4. Simon AM, Manigrasso MB, O’Connor JP. Cyclo-oxygenase 2 function is essential for bone fracture healing. J Bone Miner Res. 2002;17(6): 963-976.

Orthopedic Research and Reviews

\section{Publish your work in this journal}

Orthopedic Research and Reviews is an international, peer-reviewed, open access journal focusing on the patho-physiology of the musculoskeletal system, trauma, surgery and other corrective interventions to restore mobility and function. Advances in new technologies, materials, techniques and pharmacological agents are particularly welcome. The journal welcomes
5. Kawaguchi H, Pilbeam CC, Harrison JR, et al. The role of prostaglandins in the regulation of bone metabolism. Clin Orthop Relat Res. 1995;313: 36-46.

6. Bergenstock M, Min W, Simon AM, Sabatino C, O’Connor JP. A comparison between the effects of acetaminophen and celecoxib on bone fracture healing in rats. J Orthop Trauma. 2005;19(10):717-723.

7. Herbenick MA, Sprott D, Stills H, Lawless M. Effects of a cyclooxygenase 2 inhibitor on fracture healing in a rat model. Am J Orthop (Belle Mead NJ). 2008;37(7):E133-E137.

8. Gerstenfeld LC, Thiede M, Seibert K, et al. Differential inhibition of fracture healing by non-selective and cyclooxygenase-2 selective non-steroidal anti-inflammatory drugs. J Orthop Res. 2003;21(4): $670-675$.

9. Brown KM, Saunders MM, Kirsch T, et al. Effect of COX-2-specific inhibition on fracture-healing in the rat femur. J Bone Joint Surg Am. 2004;86-A(1):116-123.

10. Mullis BH, Copland ST, Weinhold PS, et al. Effect of COX-2 inhibitors and non-steroidal anti-inflammatory drugs on a mouse fracture model. Injury. 2006;37(9):827-837.

11. Li J, Mori S, Kaji Y, Mashiba T, Kawanishi J, Norimatsu H. Effect of bisphosphonate (incadronate) on fracture healing of long bones in rats. J Bone Miner Res. 1999;14(6):969-979.

12. Cao Y, Mori S, Mashiba T, et al. Raloxifene, estrogen, and alendronate affect the processes of fracture repair differently in ovariectomized rats. J Bone Miner Res. 2002;17(12):2237-2246.

13. Iwamoto J, Seki A, Sato Y, Matsumoto H, Tadeda T, Yeh JK. Vitamin $\mathrm{K}_{2}$ promotes bone healing in a rat femoral osteotomy model with or without glucocorticoid treatment. Calcif Tissue Int. 2010;86(3): 234-241.

14. Paulson SK, Zhang JY, Breau AP, et al. Pharmacokinetics, tissue distribution, metabolism, and excretion of celecoxib in rats. Drug Metab Dispos. 2000;28(5):514-521.

15. Paulson SK, Zhang JY, Jessen SM, et al. Comparison of celecoxib metabolism and excretion in mouse, rabbit, dog, cynomolgus monkey and rhesus monkey. Xenobiotica. 2000(7);30:731-744.

16. Villanueva AR. A bone stain for osteoid seams in fresh, unembedded, mineralized bone. Stain Technol. 1974;49(1):1-8.

17. Parfitt AM, Drezner MK, Glorieux FH, et al. Bone histomorphometry: standardization of nomenclature, symbols, and units. Report of the ASBMR Histomorphometry Nomenclature Committee. J Bone Miner Res. 1987;2(6):595-610.

18. Daluiski A, Ramsey KE, Shi Y, et al. Cyclooxygenase-2 inhibitors in human skeletal fracture healing. Orthopedics. 2006;29(3):259-261.

19. Simon AM, O'Connor JP. Dose and time-dependent effects of cyclooxygenase-2 inhibition on fracture-healing. J Bone Joint Surg Am. 2007;89(3):500-511.

20. Jeske AH. Selecting new drugs for pain control: evidence-based decisions or clinical impressions? J Am Dent Assoc. 2002;133(8): 1052-1056.

21. Bo J, Sudmann E, Marton PF. Effect of indomethacin on fracture healing in rats. Acta Orthop Scand. 1976;47(6):588-599.

22. Sudmann E, Dregelid E, Bessesen A, Morland J. Inhibition of fracture healing by indomethacin in rats. Eur J Clin Invest. 1979;9(5): 333-339.

23. Altman RD, Latta LL, Keer R, Renfree K, Hornicek FJ, Banovac K. Effect of nonsteroidal antiinflammatory drugs on fracture healing: a laboratory study in rats. J Orthop Trauma. 1995;9(5):392-400.

\section{Dovepress}

original research, clinical studies, reviews \& evaluations, expert opinion and commentary, case reports and extended reports. The manuscript management system is completely online and includes a very quick and fair peer-review system, which is all easy to use. Visit http://www.dovepress. com/testimonials.php to read real quotes from published authors. 